\title{
1 Introduction: How Do Social Media Change Social Order? The Deep Datafication of Society from Global to Local Scales (and Back Again)
}

\author{
David Herbert and Stefan Fisher-Høyrem
}

\begin{abstract}
Researching the social/media relation today must mean more than merely describing how the latest platforms work, let alone celebrating their supposedly positive potential (democratic? expressive? socializing?). It must mean at least researching how social media platforms ... have come to propose a certain version of "the social," and how users go on to enact it. It must also mean researching ... and registering the fractured spaces from where alternative proposals of "the social” might be built (Couldry \& van Dijck 2015, p. 2; emphases in the original).
\end{abstract}

The concept of "social order" is not an academic detail, still less a theoretical extravagance, but rather a highly practical term for registering how social worlds are, on the largest scale, being transformed through the interlinking of all we do on social media ... and the systems of social governance, explicit and implicit, that are emerging to manage them (Couldry, this volume).

This book addresses the relationship between social media and social order at multiple scales, providing insights into how diverse social worlds are being reshaped by social media, as well as analysis and reflection on what this means and how critical publics might respond.

From the invention of the internet, successive waves of digitally networked technologies have been welcomed by social scientists and commentators as providing the means both to widen participation in discussion of matters of common concern (the public sphere model, following Habermas, 1989/1968) and for subordinate groups to self-organise and resist forms of oppression based on media and political elites' symbolic domination of society through the mass media (the emancipatory model, following Castells, 2012). Furthermore, social scientists have identified several mechanisms through which these forms of participatory and emancipatory agency might be exercised - including the propensity of networks to elude hierarchical domination (Benkler, 2006), their capacity to enable "contraflow" from peripheral to central media producers (Cottle, 2006), and the "virality" of user-generated content, which can on occasion generate networked publics capable of challenging major corporations and even governments (Castells, 2012).

However, it is our contention that, while networked technologies do indeed sometimes enable such dialogical and emancipatory outcomes, normally they enable rather different social processes - i.e. they tend to reinforce, elaborate and further embed existing forms of social order, rather than challenge them (Boy \& Uitermark, 2019, pp. 2-3; Herbert, 2020, p. 10). Social order in this context should not be conceived as static, but rather as dynamic, constantly evolving and actively reproduced through 
continuous interaction. The tendency of networked technologies to re-enforce rather than challenge existing social order occurs partly because the networks formed through them are mostly composed on the basis of attraction, admiration and shared interest; for example, with social media networks being woven from the expressions of liking, following and retweeting etc., with those individuals who most exhibit the admired quality (and most actively promote it and often themselves), as the stars around which the network revolves, each forming a cluster with the network of clusters comprising the constellation of the platform. Platforms explicitly formed around the desire to engage with different others are comparatively rare, and often require vigilant forms of moderation to keep the discourse civil (see Herbert \& Black, 2012). Furthermore, the formation of clusters is algorithmically shaped, as algorithms embedded in the platforms constantly suggest friends, content and products we might like in iterative response to our choices. The emergent process of tailoring content to users is thus one of continuous differentiation, which at an individual level ensures we receive suggestions we are likely to like, at a collective level connects us more intricately to those we already like and are likely to like (reinforcing our filter bubble, and likely existing power relations), and is continually commercially harvested, and may be used to enable differential (and hence potentially discriminatory) treatment by businesses and government.

In Chapter 2 project advisor for CC2 and leading public intellectual on mediasociety entanglements Nick Couldry casts doubt on optimistic assessments of the impact of networked digital media for a related but different reason. Addressing the largest geographic scale possible, he asks: how does the corporate harvesting of data from networked digital devices impact on the ordering of social relations in general, at a global scale? In other words, what are the general features of a "datafied" social order? The question relates to the homophilic basis of social networks because the choices of individuals to link to networks of similar others forms a small part of the data on user activity collected by the corporations who run social media platforms and other networked digital services. On social media platforms it is used to suggest people we might know or like to connect with, and thus may shape our social networks directly; similar algorithms which drive the recommendation process are also deployed to recommend products and services based on our internet search and retail activity. Couldry's is therefore a large question, but an appropriate one within which to frame a collection which focuses on analysing specific instances of the development of how users enact social orders shaped by networked digital platforms - social media - and hence datafied - at city/site (Chapters 3 through 6), and national scales (Chapters 7 and 8).

But first, before considering Couldry's answer, why "social order" at all? Couldry argues that the concept is out of fashion, citing in support that the last major work came out in 1994 and is out of print, and giving as a possible reason the challenge to reified concepts of the social especially in the field of assessing the impacts of new technologies by proponents of actor network theory (Latour, 2005). In 
response, Couldry argues that "at a time when, through datafication, it appears that corporations and governments are intent on reconstructing social reality in ways that align with their interests, it becomes vital to pay close attention to processes of social construction" (Couldry, Ch. 2) - and that some concept of social order is essential in developing a critical account of such processes.

Furthermore, other evidence suggests social order may not be such a neglected or marginal topic in social sciences. In 2003 an American textbook on the topic appeared, with a second edition in 2009 and a well-maintained supporting website, suggesting at least modest currency of the term in US social science programs (Hechter \& Horne, 2009; https://www.sup.org/socialorder/?ref=bookurl). This collection is useful for showing the influence of the concept of social order across a range of social science disciplines, for asserting its role as "a core theoretical issue in the social sciences" and for indicating the range of ways in which the "problem of social order" - understood by the authors as how people "coordinate their actions and ... cooperate to attain common goals" (ibid. 1) is addressed through several traditions of conceptualisation and theorisation, including mobilising concepts of groups, hierarchies, markets and networks (ibid., vii-viii).

Notably absent from this collection, however, is any sustained attention to how media technologies might shape social order, which is the central question addressed in this volume, focusing on social media. The perspective also differs markedly in its Hobbesian framing - which constructs the "state of nature" as fundamentally conflictual and therefore legitimises the need for ordering mechanisms to reconcile the differing interests of individuals for the greater (individual and collective) good. In this way, the perspective aligns with what Zygmunt Bauman describes as "the gardening principle" of the modern state, as Schiel summarises the concept:

It refers to a state "managed" by its government like a garden. The gardener/ government applies rational methods based on scientific knowledge to create optimal conditions of growth for the "plants"/people (2005, p. 81).

The framing of an absence of social order as a problem that needs "solving" tends to legitimise the need for "solutions" of some kind; whether through markets or networks as "horizontal" or decentralised co-ordinating mechanisms, or through the state or some kind of hierarchy as "vertical" mechanisms of control. Bauman, in contrast, is suspicious of such mechanisms of social control, an approach exemplified by his characterisation of the modern state, which emphasises the disruptive and novel features of modern state power:

With the backbone of communal self-reproduction disintegrating or crushed, the modern state power was bound to engage in deliberate management of social processes on an unheard-of scale ... it did not concentrate the previously dispersed powers. It presided over the formation of an entirely new kind of power, or unprecedented scope, depth of ambition, depth of penetration and ambition (Bauman, 1990, p. 157). 
We think it is not exaggerating to say that Couldry sees the datafication of society as a project of similar scope, involving a parallel deepening of penetration of state and corporate mechanisms of social control. Couldry focuses on corporate data harvesting as the most ubiquitous global form of datafication, but locates this in relation to and stresses connections with state uses of digital data; for example, in China where there is less separation of state and corporate sectors and less emphasis on personal privacy to maintain that distinction than in the West. It is also where the most ambitious and overt attempt to harness big data to rank the social "trustworthiness" of citizens and distribute rewards and punishments accordingly - The Social Credit System - and hence directly harvest digital date to shape social order - is already being rolled out (Liang et al., 2018). Yet, Couldry also notes the interest of governments everywhere in harnessing digital data to police populations and shape behaviour, stressing the disproportionate impact of this on the lives of the poor and especially those relying on state welfare.

Couldry argues that the genesis of the datafied order was largely unplanned (e.g. Google's accidental discovery that it could commercially exploit internet search data, Zuboff, 2019), and that this remains partly true of its ongoing development. For while "corporate intention becomes a major factor once the advantages of an emerging datafied social order become clearer to corporations," planned or coordinated action by key players is not required for what we suggest might be termed the deep datafication of society, a process through which "the principle of discriminationthrough-data (that is, automatically harvested data from online activities) has spread right across the social terrain" (Couldry, this volume). Thus, while corporations and governments have long sought, held and used data on citizens and consumers from multiple sources, networked digital platforms enable its gathering, use and integration on an unprecedented scale, reaching deep into the everyday lives of people across the planet - hence deep datafication.

Like Herbert and Fisher-Høyrem (Chapter 4), Couldry draws on Elias to conceptualise the emergence of a datafied social order. Elias understands a "figuration" as "a structure of mutually orientated and dependent people ... the network of interdependencies formed by individuals" (Elias, 2000, p. 482). Elias argues that social order emerges through such figurations, "through the continuous interweaving of many interrelationships and connections, their progressive impact, as social actors try, successfully or otherwise, to live their lives through the web of interrelations in which they have largely no choice but to be entangled" (Couldry, this volume). Thus, what Couldry and Mejías (2019) call "data relations," referring to "relations that configure social life on a basis designed to optimise the generation and extraction of valuable data" become "a leading form of 'figuration' ... for the era of datafication.” (Couldry, this volume).

At the same time, Couldry argues that while "discrimination-through-data ... has spread right across the social terrain," resistance is neither impossible nor futile; rather "to the extent that this order is resisted by social actors, it will not unfold 
exactly as I outline here. That is the point of analysing datafied societies from the point of view of social order, to alert readers to what is under way and help them imagine what resistance might feel like." (Couldry, this volume).

Elias' concept of figuration can be applied to many kinds of social relations, especially where there is a lack of strong central social control, or social norms leave space for negotiation. But the difference in a datafied social order is the way in which virtual forms of social interaction are mediated by the properties of digital systems, in particular by social media platforms. It is on this mediation, its effects on those enmeshed, their agency and resistance, that the substantive chapters that follow Couldry's essay focus. Each examines how users enact - using Couldry and van Dijck's terms - the versions of the social proposed by social media platforms across range of scales and sites.

Drawing on the dramaturgical perspective of Erving Goffman, in Chapter 3 Boy and Uitermark investigate the self-presentation and status displays characterising the online conduct and related careers of Instagram influencers. Instagram clusters tend to centre on very few user accounts, whose style of display sets the tone for the entire cluster, and whose influence enables them to access temporary job opportunities as party hosts or event promoters. The interviews reveal a vast and stress-inducing gap between their curated Instagram "frontstage" personas and the "backstage" precarity of their offline lives and continuous intense effort required to maintain their social media profiles. These interviewees are "central users" in their Instagram clusters and the platform has become central for their livelihoods, but one that has become a hard taskmaster, requiring constant updating to maintain the users' precarious position at the pinnacle of esteem.

Similarly, in Chapter 4 Fisher-Høyrem and Herbert draw on Elias' model of the early modern royal court, analysing how local top users of Instagram in a Scandinavian town compete for the attention of users of higher status, and how this quest for affirmation involves mutual (and self-) policing, shaming, and an anxious interweaving of online and offline lives. Combining computational and qualitative methods in their investigation of local online "clusters of prestige," they argue that what is celebrated in the local social order of the "Bible belt" town - specific locations, leisure activities, family structures, religious identities - is also celebrated as prestigious and worthy of esteem across local social media clusters, so that at this site Instagram tends to reinforce the social norms and hierarchies of the pre-existing social order.

In Chapter 5 Sagorika Singha also examines the interplay of small-town dynamics with digital media - in this case the media product being not an Instagram profile but the memes produced by local online "meme collectives" in the Indian region of Assam. Memes have revived and fuelled old sentiments, providing a platform from which users seek to influence regional and national politics through insider jokes and shaming practices playing on pop-cultural references. Singha explores the ambivalence of the effects of these meme collectives on the distribution of 
power in local social and political relations. On the one hand they demonstrate a decentralisation of "agenda-setting" media power away from educated urban elites in the major cities, empowering "small town" media users. As Singha comments "if designed and received in the right way, a meme has immense potentialities to provide required value to a cause."

But on the other hand, those so empowered tend to be amongst the more privileged within local communities. Furthermore, because "memes often appropriate dominant discourses" their use can (and does, in the examples discussed) reproduce and more widely disseminate gendered, stereotyping and populist discourses. The dynamic here seems to be similar to that observed by Rajagopal (2001) of the national televising religious epics on Indian politics two decades before: new publics are created and new participants become politically engaged, but at the cost of increased "confusion" of public discourse and polarisation of political life (ibid., p. 279; see also Herbert, 2003, pp. 112-3). Social media thus reconfigures the social order in ways that allow for the emergence of new political actors, but which tends to reinforce existing social hierarchies, prejudices and divisions.

In Chapter 6 Liat Berdugo also investigates the interaction between networked digital media and contested local spaces, in this case between Israeli security services and Palestinian and Israeli activists in contested territories on the West Bank, examining the liminal space that emerges between physical and mediatised conflict. Specifically, she investigates what happens when camera recordings of civic injustices in Palestine are met with camera recordings of the resistance - a "struggle for spectral power," and the implicit recognition from all involved parties of the force carried by the online spectacle, as activists' videos are posted on their website for a potentially global audience.

Berdugo's analysis highlights gendered aspects of the conflict, especially between the "vision of and visual documentation produced by Palestinian women" and that produced by "a special unit of exclusively female soldiers called Tatzpitaniot ('The Watchers')," whose "sole job (is) to watch live video streams of the IDF's network of 1,700 security cameras mounted along key sites in the West Bank and Gaza." Berdugo argues that the framing of the activities of the Tatzpitaniot in the Israeli Defence Forces' promotional material as defenders of Israel's borders draws on an essentialised construction of Israeli women as defenders of "the land," against which Palestinian counter-surveillance is positioned as a threat. In response, Berdugo invites readers to view the conflict through and "an ecofeminist lens, which demands a consideration of how the land and women - as feminized witnesses - have both been historically subjugated by a shared history of oppression" and for "a sightline that celebrates disobedient, insurgent ways of looking: ways that visibilise the very frame of an image as a means towards new kinds of resistance in conflict." Here, the use of networked digital technologies crystallizes around and, in some ways, amplifies existing divisions, with the IDF mobilising tropes of the female guardians of the land reaching back to pioneering days, and activists invoking the potential presence of 
a global audience for their videos in an attempt to redress the power balance. Yet Berdugo also points to the possibility of the invocation of a shared narrative and way of viewing which moves beyond binary constructs of "us" and "them."

Berdugo's analysis of the gender dimensions of the "competitive videography" may also be used to suggest another perspective on Amsterdam's Instagram influencers (Boy \& Uitermark, Chapter 3). Both their leading interviewees are women, reflecting a tendency for women in their 20s and 30s to predominate among the most followed accounts on Instagram in Amsterdam (Boy \& Uitermark, 2017, p. 617). It may be that the Instagram platform, with its emphasis on the curation and projection of stylish and glamorous self-images, is one that skilled female users are amongst those most adept at exploiting to attract followers. However, as Boy and Uitermark's analysis clearly brings out, this attention comes at the price of constant effort to maintain the image, articulating the precarity of a profile based on gendered criteria of glamour and attractiveness, and in a context in which the women's working lives are precarious, dependent on their capacity to keep drawing "the right crowd" to the venues they promote.

A different downside of gendered public attention to women on social media is exposed by Soberaj and Merchant's study of Twitter mentions of US legislators (Chapter 7), and their analysis takes on an intersectional dimension as it focuses particularly on the abuse directed at female legislators of colour in the US. Their analysis reveals that different users inhabit different digital worlds, in that online shaming and harassment affects female legislators and legislators of colour far more than their white (and/or) male colleagues. In a world where social media are crucial to the outcome of democratic elections, politicians are required to display themselves on several platforms, yet exposure can have huge personal costs for female candidates, especially women of colour. Here social media serves to amplify prejudices and power imbalances within the wider social order.

Our second American case study is provided by Wanless and Berk (Chapter 8), who show how social media users are "drawn into and participating in the creation and spread of persuasive messaging," something they call an "enhanced form of propaganda" that is increasingly invasive in nature. Using data from the 2016 US presidential campaign, they examine the "organised deployment" of techniques of "participatory propaganda" to greatly amplify the impact of political messaging by harnessing the trust people place in social networks, including giving credibility to messages of questionable provenance and veracity - and indeed whose provenance has been deliberately obscured. From the propogandists' viewpoint the method is particularly efficient, as rather than requiring the constant funding of political advertisements via mass media, "participatory propaganda campaigns run as long as the cause driving it matters to its members - or rather, those administrating such groups are able to produce content that engages and provokes followers." Social media here present a threat to social order rooted in democratic debate, because the social basis of trust in networks is used by participatory propagandists to mask the 
false basis of claims, resulting in systematically distorted public communication. How then to resist self-fuelling participatory propaganda? Wanless and Berk argue that "finding ways to identify and measure engagement within these networks to understand the driving rationale, as oppose to blocking them, should be a priority for those studying liberal democracies."

The overall construction of the collection thus follows an arc from outlining the general properties of a datafied social order through a series of actor-focused perspectives which examine how roles structured by social media are performed at various sites located in European cities, entangled in contested Middle Eastern borders, and embedded in provincial Indian small-town networks, then back to an increasing focus on the general properties of social media networks revealed through our American cases, while not forgetting the human costs for the recipients of abuse (legislators of colour) or the political costs of participatory propaganda for a deliberative understanding of democracy.

Our accounts will emphasise how the principle of differential treatment embedded in a datafied social order is becoming increasingly widespread across social fields (Chapter 2), and examine a series of cases in which social media is clearly implicated in the reshaping social order in ways which align with the principle: where social media creates new precarious hierarchies of esteem maintained at high cost by those at their pinnacle (Chapter 3), reinforces existing hierarchies (Chapter 4), includes a broader range of participants in political discourse but at the expense of reinforcing local hierarchies and dominant discourses (Chapter 5), reinforces gendered constructions of national identity (Chapter 6), amplifies the abuse received by women and people of colour in leadership positions (Chapter 7) and enmeshes users in the circulation of propaganda which resonates with their preconceptions, deepening societal polarization (Chapter 8).

This arc then, as Couldry writes, will alert readers "to what is under way," but what of the potential for resistance by social actors, to help readers "imagine what resistance might feel like"? Writing this introduction in late 2020, it is hard to miss the powerful global examples of \#MeToo and \#BlackLivesMatter as cases of digitally networked global movements which have been able to provide sustained foci of resistance to abuses of power, particularly to the gendered and racialised forms of abuse identified by Soberaj and Merchant (Chapter 7). The volume lacks case studies on this scale, but rather identifies scattered sites from which such resistance could be mounted, in the spirit of Zygmunt Bauman's contention that the purpose of sociology is to imagine alternative futures (Bordoni, 2016, p. 283).

These "fractured spaces" range from the personal awareness shown by the key witnesses in Boy and Uitermark's account of Amsterdam Instagrammers, to Berdugo's eco-feminist standpoint and Wanless and Berk's appeal for more research to understand the "driving rationale" for engagement with participatory propaganda networks. The first group articulate a discontent with their lifestyle and a desire to move to more secure employment, suggesting that even those most personally 
invested in the platform maintain a critical and external perspective which allows them to imagine how things might be otherwise. The second constructs a vantage point from which deeply divided Israeli and Palestinian women can be seen to share a common history of oppression, while the third articulates the desire to understand in order to empower people to choose to change; a good vantage point from which to launch into the collection.

\section{References}

Bauman, Z. (1990). Modernity and Ambivalence. Theory, Culture \& Society, 7(2-3), 143-169.

Benckler, Y. (2006). The Wealth of Networks: How Social Production Transforms Markets and Freedom. New Haven, CT: Yale University Press.

Bordoni, C. (2016). Introduction to Zygmunt Bauman. Revue internationale de philosophie, 277(3), 281-289.

Boy, J. D. \& Uitermark, J. (2017). Reassembling the city through Instagram. Transactions - Institute of British Geographers, 42(4), 612-624.

Boy, J. D. \& Uitermark, J. (2019). Theorizing Social Media with Elias: Status Displays, Mutual Monitoring, and the Genesis of New Sensibilities. SocArXiv. July 11. doi:10.31235/osf.io/phm5x.

Castells, M. (2012). Networks of Outrage and Hope. Cambridge: Polity.

Cottle, S. (2006). Mediatized Conflicts. Buckingham: Open University Press.

Couldry, N. \& van Dijck, J. (2015). Researching Social Media as if the Social Mattered. Social Media + Society, 1(2), 1-7.

Elias, N. (2000). The civilizing process: Sociogenetic and psychogenetic investigations (E. Jephcott, Trans. Revised ed). Oxford: Blackwell Publishers.

Habermas, J. (1989/1968). The Structural Transformation of the Public Sphere. Cambridge: Cambridge Univresity Press.

Hechter, M. \& Horne, C. (2009). Theories of Social Order. Stanford, CA: Standford University Press.

Herbert, D. (2020). Social Media and Spatial Justice: Instagram, Status Competition and the Deepening of Urban Exclusion in Northern Europe. In Watson, S. (Ed.), Spatial Justice in the City (pp. 7-25). London: Routledge.

Herbert, D. \& Black, T. (2012). What Kind of Global Conversation? Participation, Democratic Deepening and Diplomacy: an examination of mediated global talk about religion and politics. In Gillespie, M. \& Webb, A. (Eds.), Diasporas and Diplomacy: Cosmopolitan Contact Zones at the BBC World Service (1932-2012) (pp. 211-229). Routledge.

Latour, B. (2005). Reassembling the Social. Oxford: Oxford University Press.

Liang, F., Das, V., Kostyuk, N., \& Hussain, M. (2018). Constructing a Data-Driven Society: China's Social Credit System as a State Surveillance Infrastructure. Policy and Internet, 10(4), 415-453.

Rajagopal, A. (2001). Politics after Television: Hindu Nationalism and the Reshaping of the Public in India. Cambridge: Cambridge University Press.

Zuboff, S. (2019). The Age of Surveillance Capitalism. London: Profile Books. 